\title{
Predictive mapping of mechanical properties of alterites through continuous electrical resistivity measurements
}

\author{
Jean Christophe Gourry, Research Division, BRGM, BP 6009, 45060 Orléans, France \\ Robert Wyns, National Geological Survey, BRGM, BP 6009, 45060 Orléans, France \\ François Lebert, Dpt of Applied Geophysics, BRGM, BP 6009, 45060 Orléans, France
}

\begin{abstract}
Introduction
Basement rocks constitute $25 \%$ of the surface geology of France. Throughout the geological record, and particularly during the Early Cretaceous and Paleogene, these rocks underwent significant weathering to form alterites more than $50 \mathrm{~m}$ thick in places. Later erosion incised valleys in the alterites, which is why, in schistose areas, one may find aggregate quarries very close to clay workings (for brick manufacture), the former being in the valley bottoms (minimum weathering) and the latter on the plateaus (maximum weathering). The aim of this research work is to assess the mechanical properties of these surface alterites in order to draw up maps for use in civil engineering sectors, such as excavation work for major communication routes (roads, etc.) and laying underground pipes and cables (gas, electricity, telecommunication lines).
\end{abstract}

\section{Theoritical basis}

The basis of the study is the assumption that a relationship exists between the erosion thickness " $\mathrm{dz}$ " and the degree of weathering (figure 1), the parameter "dz" being the difference between the altitude of reconstructed paleosurfaces and that of the current digital elevation model (Wyns, 1991). It consists in establishing a correlation between "dz" and the mechanical strength of alterites in order to geostatistically extrapolate a map of surface mechanical strength (figure 2). An estimated confidence interval for the calculated mechanical strength is assigned to each map point. Furthermore, because penetrometer measurements are very expensive for large-scale surveys, we chose a less-expensive physical parameter - electrical resistivity - for correlating mechanical strength.

\section{Continuous resistivity measurements and penetrometers}

An electrical- resistivity survey was carried out over several tens of kilometres along characteristic weathering profiles, as complete as possible, working from the valley bottom (no weathering) towards the plateau (maximum weathering). The equipment used (figure 3 ) was a quadripole profiling device with six spacings of the potential dipole (capacitive electrode recording) relative to the current dipole (electrostatic injection). With this system it is possible to obtain continuous measurements of the six resistivities simultaneously (figure 4). A semi-automatic spatial correlation using differential GPS provided precision to the nearest few tens of centimetres for $x, y$ and $z$. Mechanical strength was measured along the electrical profiles using a manual penetrometer and an average measuring interval of $5 \mathrm{~m}$ inheight (about $250 \mathrm{~m}$ in distance). The density of resistivity profiles is $1 \mathrm{~km} / 5 \mathrm{~km}^{2}$. The measurement of the penetrometer used as the mechanical strenght is taken at $1.5 \mathrm{~m}$. 


\section{Results}

The mechanical strength and electrical resistivity correspondence curves as a function of erosion thickness reveal a correlation between the two parameters (figure 5). Mechanical strength increases proportionally with resistivity as one moves down the valley. Several correlation sections are identified:

- in the valley bottom, electrical resistivity and mechanical strength values are the highest and almost constant for the fresh rock beneath the alterites;

- moving up slope along the weathering profile, the resistivity and mechanical strength values decrease rapidly as a function of "dz" to reach a minimum at the isalterite/alloterite interface. This section is composed of isalterites where weathering has caused a loss of mass, but not a loss of volume;

- above the interface, a slight inversion of the regression line gradient is observed both for mechanical strength and electrical resistivity and for erosion thickness: this section is made up of alloterites where compaction has caused a loss of both mass and volume. A progressive increase in the proportion of quartz grains is observed in these rocks, which causes an increase in hardness and mechanical resistivity on the plateau.

\section{Conclusion}

This correlation between resistivity and soil hardness exists on all the profiles carried out in the area. Nevertheless the the coefficients of the linear fitting are different on each profile.

This study forms the first step towards applying these results to compiling a ground hardness predictive map. The next step will be to study the spatial variation of this correlation between electrical resistivity and soil hardness, and then to extrapolate to the whole map.

\section{References}

Wyns R. (1991) - L'utilisation des paléosurfaces continentales en cartographie probabilistes. Géologie de la France, $n^{\circ} 3, p 3-9$. 


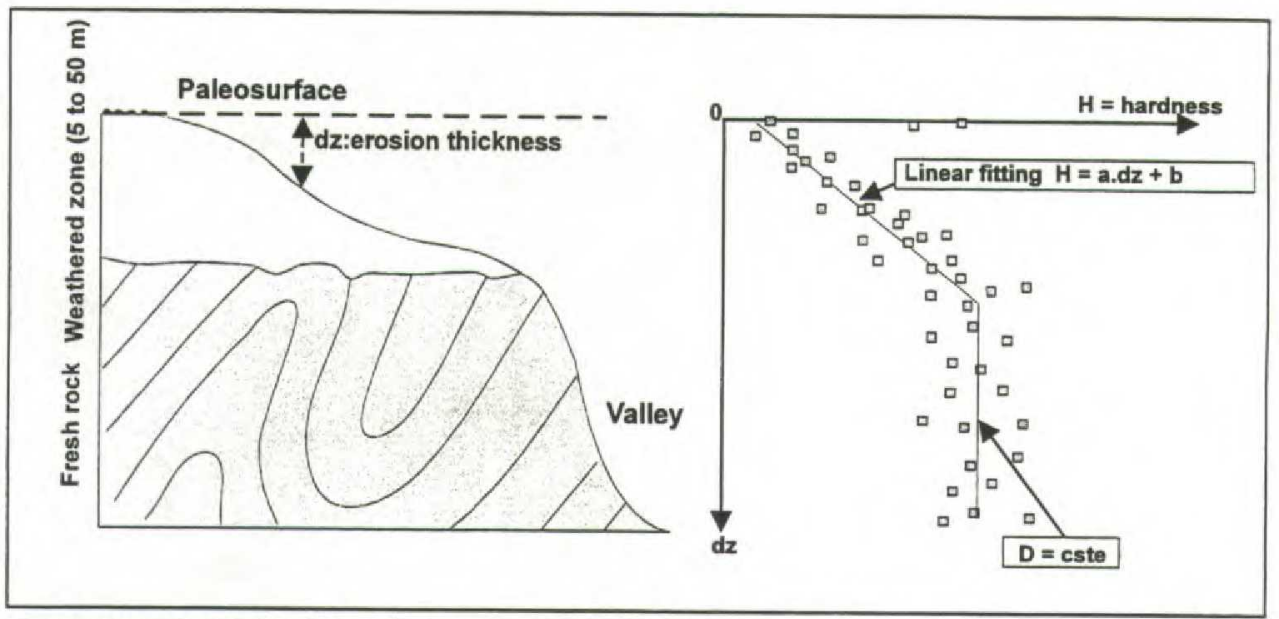

Figure 1 - Principle of corellation between $\mathrm{dz}$ and a parameter linked to the degree of weathering (hypothetical case)

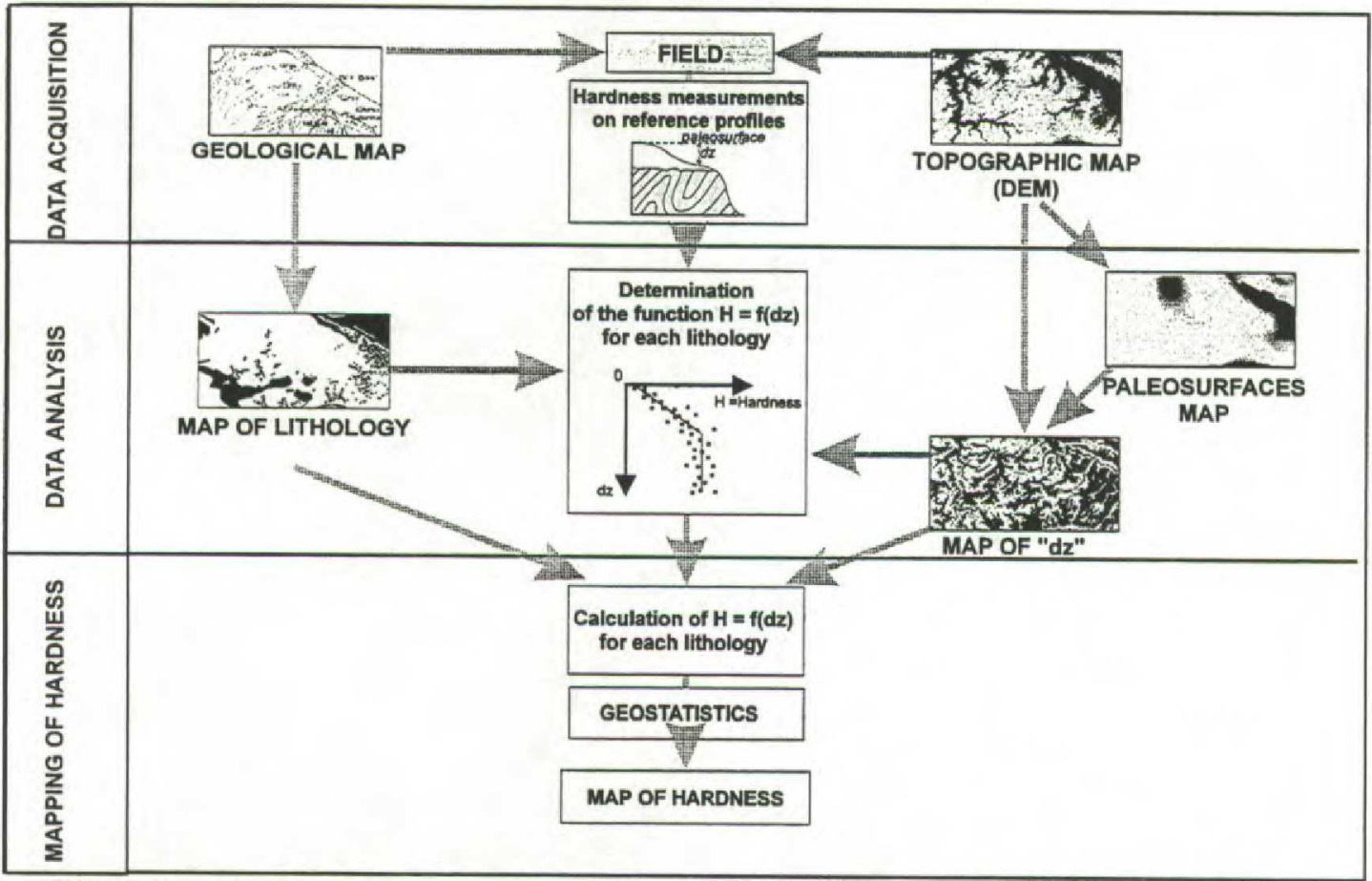

Figure 2 - Flowchart for the predictive hardness map in a weathered basement area.

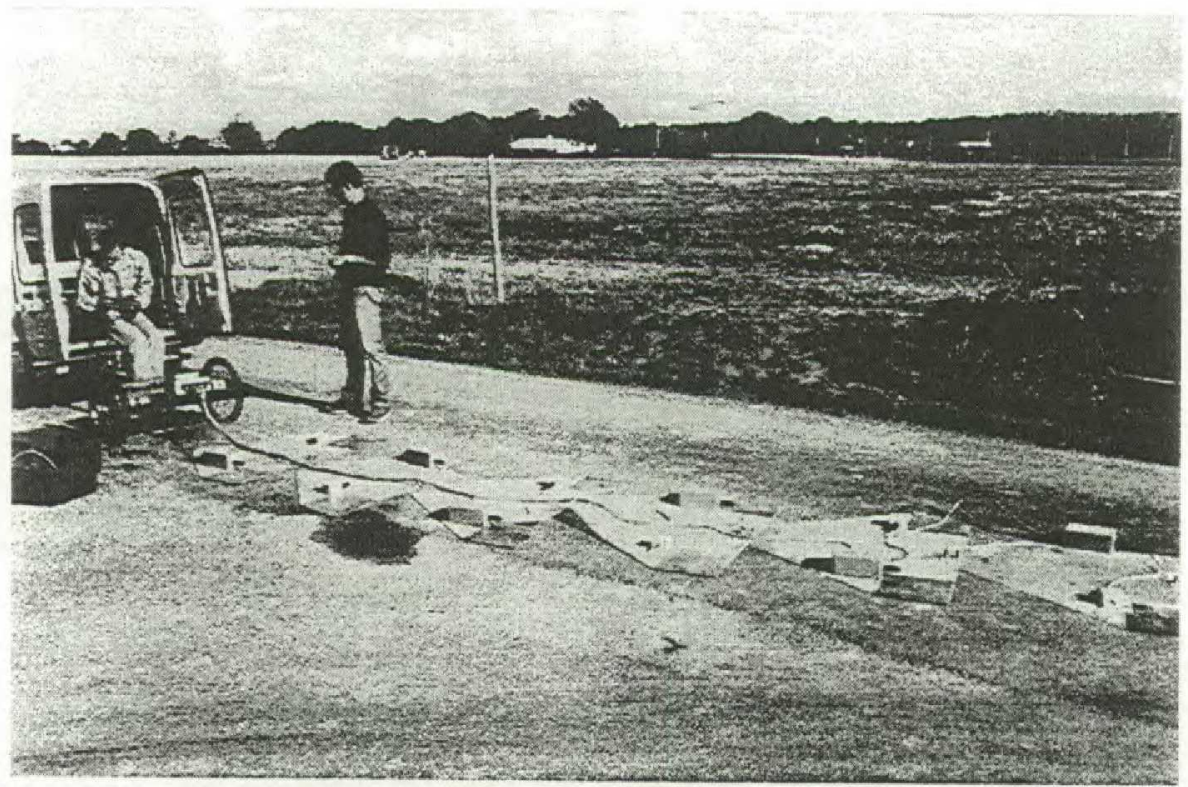

Figure 3 : Continuous electrical resistivity equipment : Iris Instruments CORIM 


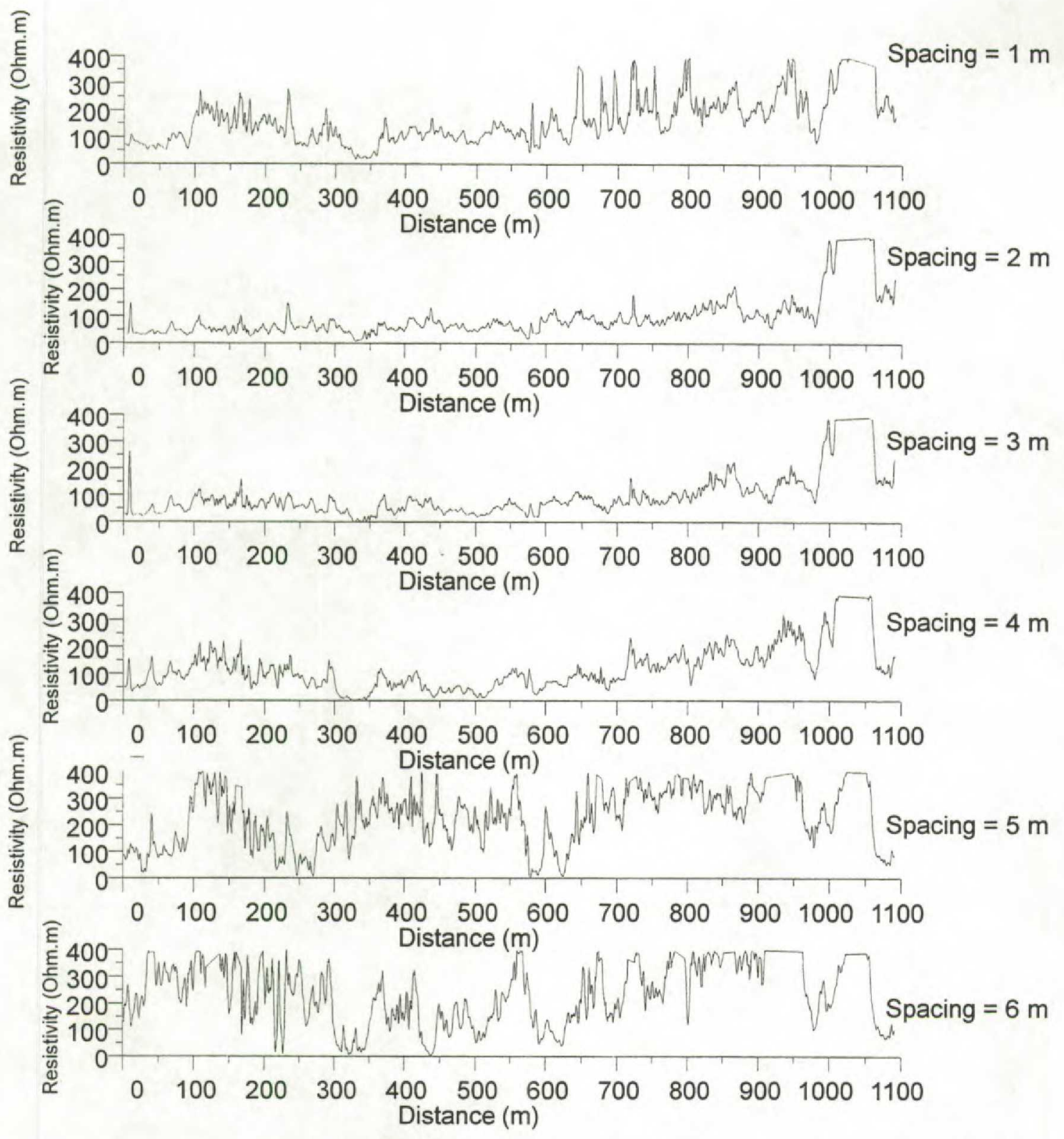

Figure 4 : Example of continuous resistivity profiles for the 6 measurement spacing.

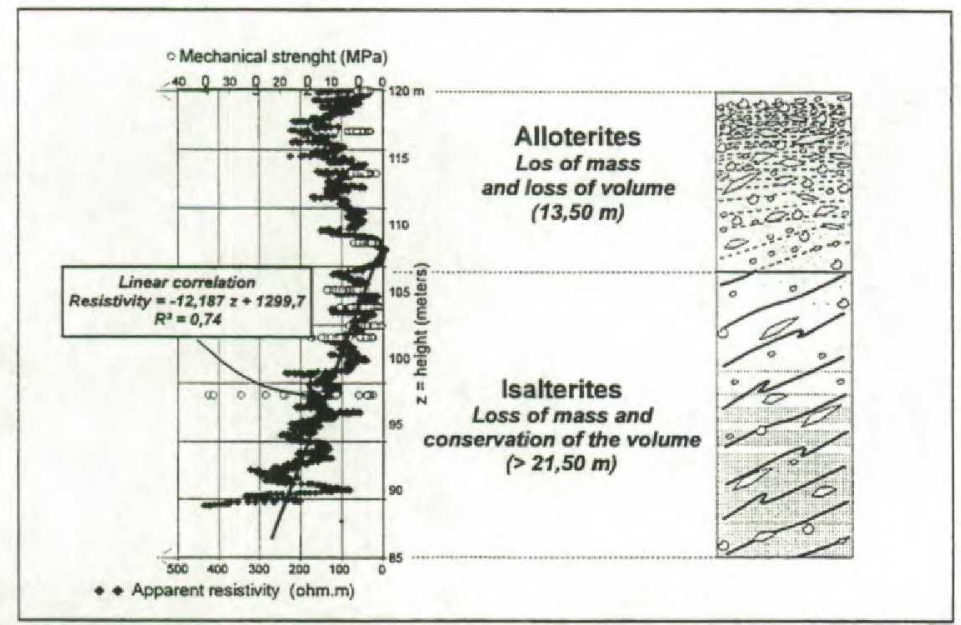

Figure 5 -Sainte-Christine (Maine-et-Loire) - Electrical resistivity profile and penetrometer readings (Measurements financially supported by the Conseil Régional des Pays de Loire) 